on the withdrawal of life-prolonging treatment were unknown, whereas Dianne was intelligent and competent, and had clearly articulated views on how she wanted her life to end. It is odd, perhaps, given that Terri would know nothing of the court's decision, that the outcome hinged on what her husband and parents claimed her wishes would have been, as a result of the so-called substituted judgement test. By contrast, the views of Dianne, who went on to suffer greatly before she died, were largely irrelevant and trumped by the possibility of harm to others.

The law moves in ways that are mysterious to many. Both these fascinating books, although dealing with different jurisdictions and issues, contribute to our understanding of the most important ethical challenges that lawyers will face in the coming decades.

Emily Jackson is professor of law at the London

School of Economics and Political Science,

Houghton Street, London WC2A 2AE, UK.

\title{
Charting the water's edge
}

Coast Lines: How Mapmakers Frame the
World and Chart Environmental Change
by Mark Monmonier
University of Chicago Press: 2008. 224 pp.
$\$ 25$

Coastal margins are drawn as precise lines on maps, yet anyone who has walked on a beach knows that coastlines are unstable. Cliffs, rocks and sands change under the influence of tides, storms, tectonic movements, global climate change and other natural and artificial phenomena.

Mark Monmonier, professor of geography at the Maxwell School of Syracuse University in New York, seeks to inform the public about how cartography and society intersect. He wishes us to look closely at maps, to recognize which features are shown or missing, and understand why. In Coast Lines, he offers an assortment of eclectic and fascinating information about how coastlines have been defined, determined and depicted, focusing on the United States in the twentieth century.

Different maps and charts of the same coastal area show different cartographic coastlines. Monmonier calls our attention to four types, explaining that each is a human construct designed to serve a specific purpose, and the result of many observations and assumptions (the latter sometimes gaining the upper hand). One cartographic coastline is the high-water line visible from offshore. Another, introduced in the nineteenth century to aid safe navigation, is the low-water line. Two are more recent: storm surge lines are designed mainly for evacuation planning and flood insurance, and inundation lines describe the plausible effects of changing geological and meteorological conditions.

Monmonier discusses the international boundaries of territorial waters. These comprise the region beyond a nation's coastline, however defined, in which that nation has sovereignty, where it can "enforce laws, levy taxes, and exclude foreign vessels not pursuing expeditious 'innocent passage' along the coast or into a port”. Under pressure from military and economic quarters, territorial waters have, in recent decades, been extended from the traditional 5.5 kilometres to 22 kilometres from shore.

Coast Lines introduces the exclusive economic zone (EEZ) in which maritime nations can "manage fisheries, mine the sea bed, and extract oil and natural gas" but cannot exclude foreign vessels. The EEZ extends 370 kilometres from shore, except where it encounters the EEZ of another nation, in which case the boundary is drawn equidistant between the two coastlines. Islands can affect where the line is drawn. For instance, because of the position of Key West and the Dry Tortuga islands off the southwestern coast of Florida, the compromise boundary between the United States and Cuba is much farther south than would be expected.

To show that "good cartography is seldom cheap and rarely happens overnight", Monmonier tells the story of the ambitious International Map of the World project. Following a German geographer's proposal at an international conference in 1891, cartographers from the industrialized nations agreed to produce a series of maps with uniform projection, symbols, style, scale and technique, which would adequately describe all of the mountains, rivers and key coastal features of the world. When complete, the mosaic of assembled 'millionth maps' drawn to a scale of 1:1,000,000 — would have covered more than 185 square metres (half the size of a basketball court) at a cost of $£ 100,000$ (US\$200,000), a significant sum at the time. Some maps were eventually produced but, with most nations reluctant to pay their share and with two intervening world wars, this grand project ended in a whimper in the second half of the twentieth century.

The failure of the International Map of the World project can, to some extent, be explained by emerging technologies that made the old standards obsolete. Some advances have revolutionized data collection and display, and some (such as intercontinental ballistic missiles) expanded the military's need for maps that were increasingly accurate and sophisticated. Monmonier has good knowledge of cartographic technologies. In a section on overhead imaging, he introduces the problem of consolidating images taken from different angles and discusses techniques for remote sensing. In another chapter he surveys the types of electronic chart that are now available.

Today, the mapping of coastlines has environmental and political implications. Proposing that cartographers can document global climate

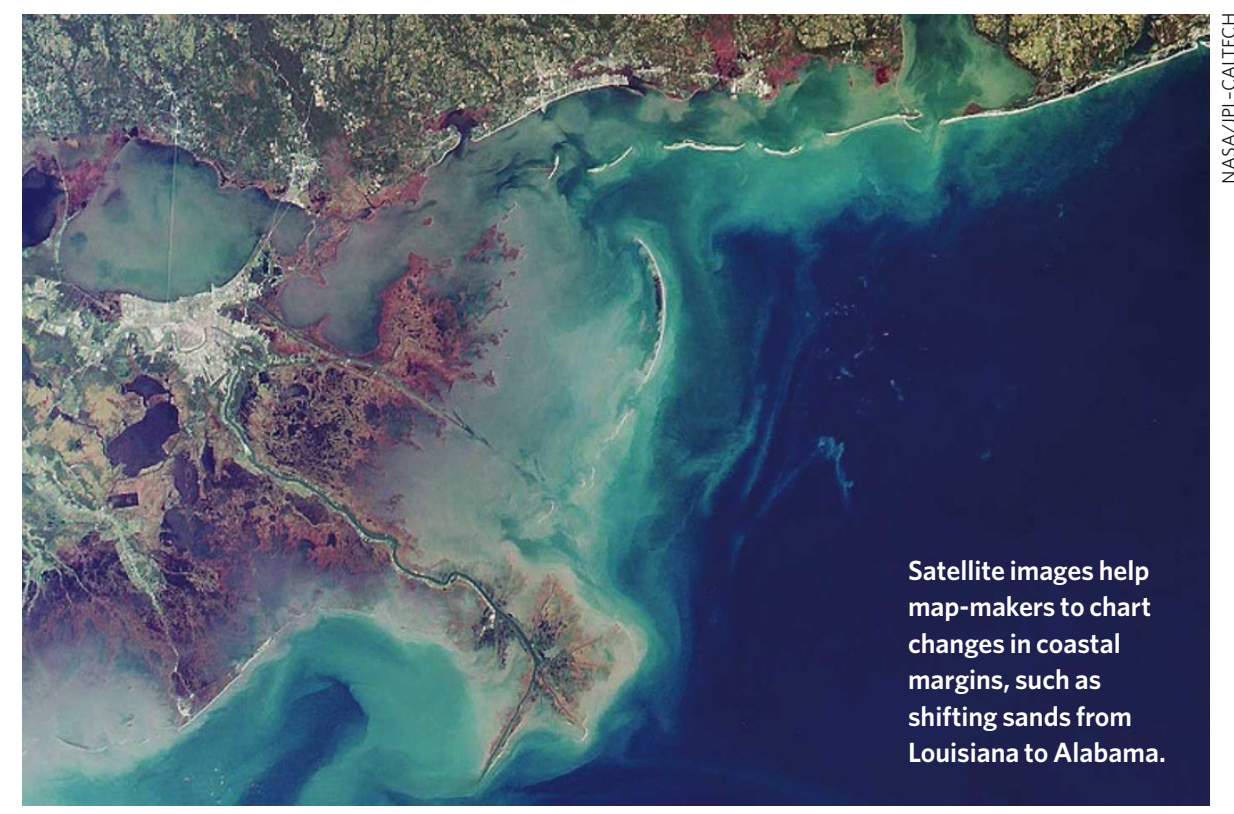


change, Monmonier juxtaposes two charts of the Outer Banks of North Carolina that show how the coastline in this area has receded over the past 125 years. Turning to predictive cartography - that is, maps and charts that indicate the probable future effect of rising seas and coastal subsidence - he admits that their foundations incorporate "multiple sources of uncertainty". Monmonier acknowledges the sensitive political nature of materials of this type. For example, although he has seen the latest maps of tidal marshlands prepared by the US Environmental Protection Agency, he is prevented from discussing them before their authorized release.

By highlighting a selection of topics, Coast Lines may succeed in its goal of getting the public to think about what maps show and why. However, Monmonier cautions prospective navigators to be aware that modern global-positioning technology enables them to know their latitudes and longitudes with greater precision than the scientists who made their maps in the first place.

Deborah Jean Warner is curator of the physical sciences collections at the National Museum of American History, Smithsonian Institution, Washington DC 20013-7012, USA.

\section{Changing perceptions of light}

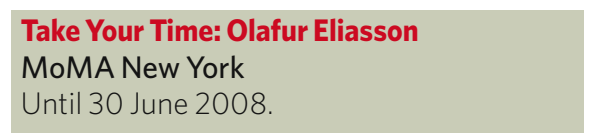

The vast foyer of New York's Museum of Modern Art (MoMA) is being dive-bombed by a small electric fan. Suspended from the ceiling by wire, it propels itself on an erratic course, buzzing over the spectators like a giant insect. Rather more calming is the title work of the current exhibition, Take Your Time, by the Danish-Icelandic artist Olafur Eliasson. It features a 12-metre-wide mirrored disc, positioned off-kilter so that as it slowly revolves it distorts the lines of the room. Hypnotic and unsettling, it is best experienced while lying on the floor.

Eliasson is an experimental artist who engages with science and the natural world. In 2003, he filled the immense Turbine Hall of London's Tate Modern gallery with a giant artificial sun made of 200 yellow lamps, mirrors and mist. Its warm glow induced crowds to recline on the gallery floor as if basking on a beach.

Fascinated by our perception of visual effects, Eliasson co-hosted a conference at Columbia University, New York, on 'The Colors of the Brain' to coincide with his 38-piece exhibition. The artist led his audience through an experiment designed to induce optical after-images, asking them to gaze into the bright lights overhead, then stare for a minute at a bottle placed on a chair, and then look at a blank screen. "The pink colour you see is the colour of blood in the eyes," he explained. Both scientists and art historians took part: neuroscientist David Eagleman discussed optical illusions and synaesthesia, and the string theorist Brian Greene made a valiant effort to explain his own abstract work.

"Science," Greene asserted, "reveals a reality different from what we perceive." Eliasson similarly questions our precarious notion of what is external and what is created in the mind of the perceiver. His $360^{\circ}$ Room For All Colours

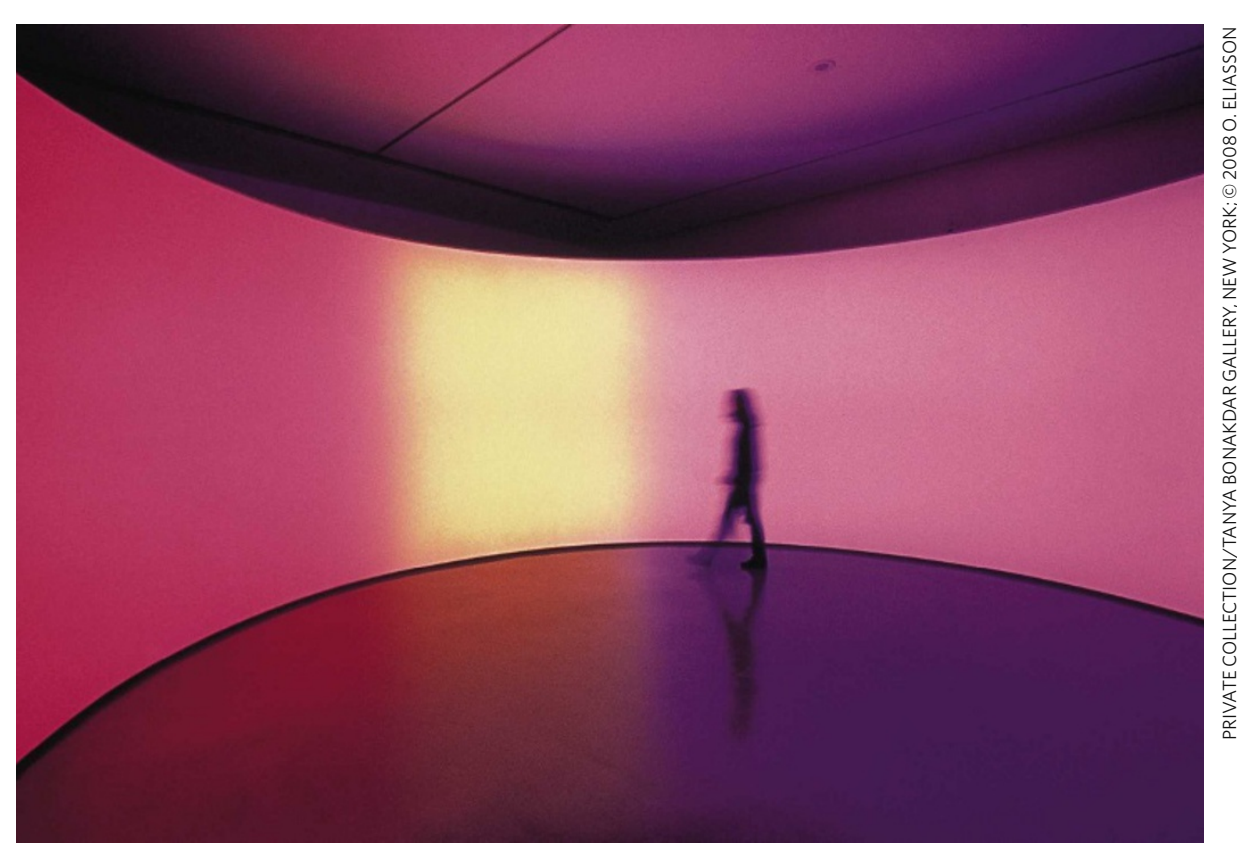

Olafur Eliasson's $360^{\circ}$ Room For All Colours explores how our minds perceive the external world.

— on view at MoMA - is a backlit drum of projected light that shines bright pink, bleeds to white, then turns electric blue. The colours seem to loiter in the mind's eye even after they have gone. Another room is starkly lit by flashes of different tones of white (some cool, others warm), the subtle changes in hue revealing the white cube gallery space to be less of a neutral background than it might initially appear.

Two rooms display Eliasson's maquettes and architectural models. Contrasting with the minimalist museum installations, these give us a glimpse inside Eliasson's working mind - the rooms are a crazy mix of revolving spheres, kaleidoscopes, geodesic domes and chandeliers made of shards of mirrored glass.

Much of Eliasson's work deals with the intersection of natural and mechanical elements. In Your Strange Certainty Still Kept, an aggressive strobe light freeze-frames water droplets as they sprinkle into a trough from a perforated hose. The stationary drops sparkle and glitter, as if suspended in space. In Beauty, gallery viewers may walk through a fiery, pulsating rainbow curtain of fine mist that is illuminated by a single spotlight. In Reversed Waterfall, a makeshift stack of metal bins, pumps and jets are assembled to force the water to flow uphill.

In late June, and on a different scale, the city's Public Art Fund will launch Eliasson's US\$15-million New York City Waterfalls project, a series of four enormous and noisy man-made torrents measuring between 27 and 37 metres high. They will be located under the Brooklyn Bridge and at other sites along the East River. It will be the largest art installation in the city since Christo filled Central Park with his saffron-coloured Gates in 2005 and, for the few days that this aqueous extravaganza coincides with his retrospective, Eliasson's dominance of New York's art scene will be total.

Christopher Turner is a writer based in New York. 